\title{
PENERAPAN RELIABILITY CENTERED MAINTENANCE (RCM) PADA MESIN RIPPLE MILL \\ ${ }^{(1)}$ Indra Hasan, ${ }^{(2)}$ Denur, ${ }^{(3)}$ Legisnal Hakim, \\ (1,2) Prodi Mesin Otomotif - Fak. Teknik Universitas muhammadiyah Riau \\ (3) Prodi Teknik Mesin Fak. Teknik - Universitas Muhammadiyah Riau \\ E-mail : indrahasan@umri.ac.id
}

\begin{abstract}
Reliability Centered Maintenance (RCM) is a process to be able to determine the type of maintenance that is appropriate in the context of operations and the consequences of failure for each asset on the production machine. Ripple Mill machine is a production machine that functions as a palm kernel crusher to separate the shells from the palm kernel. Failure in the Ripple Mill machine impedes the production process which results in a decrease in production capacity. This research was conducted to identify the Failure Mode Effect Analysis (FMEA) and Logic Tree Analysis (LTA) and calculate the failure rate of the Ripple Mill machine. Based on the analysis of the Failure Mode Effect Analysis (FMEA) identified 17 failure modes with mechanical failure of $35.30 \%$, Electrical $29.40 \%$ and Instrumentation $35.30 \%$. Logic Tree Analysis results from a total of 17 failure modes show that $0 \%$ category A, $11.76 \%$ of which are category B, 35.29\% category C, $23.52 \%$ category $D / B$ and $29.41 \%$ category $D / C$. The results of the damage time interval regression of each Ripple Mill, Ripple Mill 3 machine in 2014 bheta value is 0.32057658 and Ripple Mill 3 in 2015 the bheta value is $0.149883<1$ and the value of Ripple Mill 4 in 2014 is 0.0286688 whereas Ripple Mill 42015 is $0.065800367<1$, the failure rate will decrease with time, so the maintenance used is Predictive maintenance which is the level of maintenance being carried out to restore and restore the system in a ready state by providing repairs for damage which has led to a decline in reliability.
\end{abstract}

Keywords: Failure Rate, FMEA, LTA, Maintenance, Predictive, Reliability, Ripple Mill

\begin{abstract}
Abstrak
Reliability Centered Maintenance (RCM) merupakan suatu proses untuk bisa menentukan jenis pemeliharaan yang sesuai dalam konteks operasi dan konsekuensi kegagalan untuk masingmasing asset pada mesin produksi. mesin Ripple Mill adalah salah satu mesin produksi yang berfungsi sebagai pemecah biji sawit untuk memisahkan cangkang dengan inti sawit. Kegagalan pada mesin Ripple Mill menghambat jalannya proses produksi yang berdampak pada penurunan kapasitas produksi. Penelitian ini dilakukan untuk mengidentifikasi Failure Mode Effect Analysis (FMEA) dan Logic Tree Analysis (LTA) dan menghitung failure rate dari mesin Ripple Mill. Berdasarkan analisis Failure Mode Effect Analysis (FMEA) mengidentifikasi 17 Failure mode dengan kegagalan mechanical sebesar 35,30 \%, Electrical 29,40 \% dan Instrumentation 35,30 \%. Hasil Logic Tree Analysis dari total 17 failure mode menunjukkan bahwa 0\% kategori A, $11,76 \%$ diantaranya adalah kategori B, 35,29\% kategori $C, 23,52 \%$ kategori D/B dan 29,41\%
\end{abstract}

SURYA TEKNIKA Vol. 6 No. 1, Desember 2019: 43-48 
kategori D/C. Hasil regression interval waktu kerusakan dari masing-masing mesin Ripple Mill, Ripple Mill 3 tahun 2014 nilai bheta adalah 0,32057658 dan Ripple Mill 3 tahun 2015 nilai bheta sebesar 0,149883 < 1 dan nilai betha Ripple Mill 4 tahun 2014 adalah 0,0286688 sedangkan Ripple Mill 4 tahun 2015 adalah sebesar 0,065800367 < 1, maka laju kegagalan akan berkurang seiring bertambahnya waktu, Jadi pemeliharaan yang di gunakan adalah Predictive maintenance yang merupakan perawatan tingkat sedang dilaksanakan untuk mengembalikan dan memulihkan sistem dalam keadaan siap dengan memberikan perbaikan atas kerusakan yang telah menyebabkan merosotnya tingkat keandalan.

Kata Kunci : Failure Rate, FMEA, LTA, Maintenance, Predictive, Reliability, Ripple Mill

\section{Pendahuluan}

PT. Perkebunan Nusantara V merupakan perusahaan yang bergerak dibidang industri kelapa sawit, salah satu perusahaan ini berada di Sei Galuh Kabupaten Kampar yang mengelola kelapa sawit menjadi minyak mentah kelapa sawit atau Crude Palm Oil (CPO) serta inti sawit. Pada proses pengolahan kelapa sawit PKS Sei Galuh memiliki beberapa stasiun pengolah yaitu stasiun Tandan Buah Segar, stasiun Sterilizer, stasiun Thresser, stasiun Press, stasiun Klarifikasi dan stasiun Kernel. Ripple Mill terdapat pada stasiun Kernel. Fungsi dari Ripple Mill ini adalah sebagai pemecah atau pemisah cangkang dari inti biji sawit dengan memanfaat kan gaya sentrifugal (menjauhi pusat putaran) yang dihasilkan dari ripple mill, sehingga biji keluar dari rotor dan terbanting dengan kuat yang menyebabkan cangkang pecah,. Kerusakan yang terjadi pada Ripple Mill ini disebabkan oleh beberapa faktor yaitu jenis dari buah kelapa sawit yang berkulit tebal atau jenis sawit Dura, serta pengisian nut yang terlalu banyak yang mengakibatkan rotor dan plat bergerigi mengalami keausan sehingga ripple plate tumpul dan rotor rod bengkok yang menyebabkan pemecahan tidak efektif. Faktor selanjutnya adalah pengoprasian Ripple Mill yang berlebihan melewati masa pakai yang di rekomendasikan dari pabrikan ripple mill. Kerusakan yang terjadi pada Ripple Mill ini mencapai 13 kali kegagalan dalam kurun waktu satu tahun. Kerusakan ini di dominan dengan kerusakan Rotor Ripple Mill dan Ripple Plate

\section{Tinjauan Pustaka}

RCM adalah sebuah metode untuk menentukan tugas-tugas pemeliharaan yang akan menjamin sebuah perancangan sistem keandalan. RCM berfungsi untuk mengatasi penyebab dominan dari kegagalan yang nantinya akan membawa pada keputusan maintanance yang berfokus pada pencegahan terjadinya jenis kegagalan yang sering terjadi. Adapun langkah-langkah penerapan Reliability Centered Maintenance adalah sebagai berikut (Mourbray 1997):

a. Menentukan penyebab terjadinya kegagalan dengan menggunakan fault tree analysis (FTA). Bertujuan untuk memperoleh probabilitas kegagalan dan menentukan komponen kritis yang rawan terhadap kegagalan.

b. Mengembangkan kegiatan analisis dengan Failure Mode Effect Analysis (FMEA), seperti menentukan prioritas equipment yang perlu di maintain.

c. Mengklasifikasikan tingkat konsekuensi kegagalan. 
d. Mengambil keputusan RCM dengan mengklasifikasikan kebutuhan tingkatan maintenance.

e. Mengimplementasikan keputusan pemeliharaan berdasar RCM.

f. Melakukan evaluasi dari hasil usulan pemeliharaaan.

RCM mengklasifikasikan konsekuensi kegagalan menjadi empat kelompok, yaitu:

a. Konsekuensi kegagalan tersembunyi

Kegagalan yang termasuk dalam konsekuensi ini mempunyai dampak kegagalan yang berlipat dan lebih serius seperti pada komponen yang tidak aman karena tersembunyi atau tidak diketahui oleh operator.

b. Konsekuensi keselamatan

Kegagalan yang terjadi berdampak pada keselamatan operator.

c. Konsekuensi operasi

Kegagalan yang terjadi mengakibatkan konsekuensi operasi yaitu produk, keluaran, biaya operasi dan biaya perbaikan serta dapat mematikan sistem atau berhentinya proses produksi.

d. Konsekuensi non operasi

Kegagalan yang terjadi tidak berdampak pada keamanan ataupun produksi, namun berdampak pada biaya langsung dan dampaknya tergolong kecil.

\section{METODE PENELITIAN \\ 1. Metode Pengumpulan Data \\ Pengumpulan data yang diperlukan \\ dilakukan dengan cara sebagai berikut:}
1) Wawancara
2) Observasi
3) Studi Pustaka
4) Studi Dokumen

\section{Variabel Penelitian}

Data yang dibutuhkan dalam penelitian ini adalah:

1) Data lamanya downtime mesin-mesin di stasiun Ripple Mill

2) Data interval waktu antar kerusakan komponen di stasiun Ripple Mill

3) Data waktu penggantian komponen mesin di stasiun Ripple Mill

\section{Pengolahan Data}

Penelitian dilakukan dengan penerapan Reliability Centered Maintenance ( RCM ) pada Ripple Mill ini akan dilakukan secara bertahap yang tersususn dalam langkah berikut :

1. Mengumpulkan data-data kerusakan mesin Ripple Mill dan komponennya di PKS PT.PN V Sei galuh yang terjadi selama tahun 2014 dan 2015.

2. Melakukan uji distribusi data, menghitung parameter Weibull untuk tiap data.

3. Menghitung reliability, availability, MTBF, laju kegagalan,

4. Menganalisis karakterisitk kegagalan: reliability, availability, laju kegagalan dan MTBF.

5. Menentukan interval penggantian optimum masing-masing komponen.

Merancang strategi pemeliharaan.

Perhitungan Total Minimum Downtime

\section{Analisa Kualitatif}

Penentuan Sistem dan pengumpulan Data Mesin Ripple Mill memiliki 3 sistem, yaitu sistem elektrik motor, sistem mekanik dan sistem kontrol. Suatu Mesin Ripple Mill dapat bekerja jika semua sistem yang ada itu berfungsi dengan baik. (MachineWeb, 1999). Pada tahap ini dilakukan penentuan level (komponen, sistem, atau plant) yang akan dianalisis dengan menggunakan Metode RCM dan melakukan pemilihan sistem jika semua plant/fasilitas tidak akan diteliti. Penentuan sistem ini harus berdasarkan kriteria RCM. Pada penelitian ini, sistem yang terpilih adalah sistem mekanik. Setelah sistem ditentukan, maka langkah selanjutnya adalah mengumpulkan 
informasi mengenai sistem yang akan ditelti. Adapun data spesifikasi komponen Ripple Mill yang ada di Pabrik kelapa sawit PT. Perkebunan Nusantara V PKS Sei Galuh yaitu sebagai berikut :

$\begin{array}{ll}\text { Mesin } & : \text { Ripple Mill } \\ \text { Kapasitas } & : 6 \text { Ton/jam } \\ \text { Model } & : 1613 \mathrm{HJ} \\ \text { Panjang mesin } & : 525 \mathrm{~cm} \\ \text { Lebar mesin } & : 240 \mathrm{~cm} \\ \text { Tinggi mesin } & : 546 \mathrm{~cm}\end{array}$

Konsumsi daya $\quad: 15 \mathrm{hp} / \mathrm{TEFC}$ motor

\section{Penentuan Fungsi Sistem Dan Kegagalan Fungsional}

Fungsi sistem dan kegagalan fungsional dapat diketahui berdasarkan diskripsi sistem, informasi kerusakan yang terjadi, dan pengamatan secara langsung terhadap sistem yang diteliti. Pada tahapan ini, dilakukan analisis mengenai kegagalan fungsional yang terjadi pada sistem yang diteliti, penjelasan mengenai kegagalan, komponen yang terkait serta hubungan antar komponen pada sistem tersebut. Hasil yang didapatkannya adalah informasi mengenai jenis kegagalan atau kerusakan yang terjadi pada sistem. Berikut ini adalah beberapa kemungkinan penyebab kegagalan (Failure
Mode) yaitu:

1. Keausan Rotor Rood,

2. Keausan pada Ripple plat,

3. Kerusakan Bearing,

4. Masalah pengoperasian,

5. Keausan Fan Bel

6. Kerusakan Motor listrik

Selanjutnya seluruh komponen failure mode tersebut dianalisa agar dapat diketahui lebih detail bagaimana suatu komponen dalam sistim Pemecahan dapat mengalami kegagalan dengan membuat analisa failure mode nya melalui information worksheet

\section{Failure Mode And Effect Analysis (FMEA)}

Mode kegagalan (failure mode) merupakan suatu keadaan yang dapat menyebabkan kegagalan fungsional. Mode kegagalan tersebut dapat mencakup semua kegagalan yang mungkin terjadi. Sehingga apabila mode kegagalan dapat diketahui maka dampak kegagalan dari suatu sistem dapat tergambarkan. Selanjutnya dapat digunakan untuk menentukan konsekuensi dan memutuskan apa yang akan dilakukan untuk mengantisipasi, mencegah, mendeteksi, dan memperbaiki. (Samatis, 2003). FMEA dapat dilihat pada tabel $\mathbf{4 . 2}$ 
Tabel 4.2 Failure Mode AndEffect Analysis (FMEA)

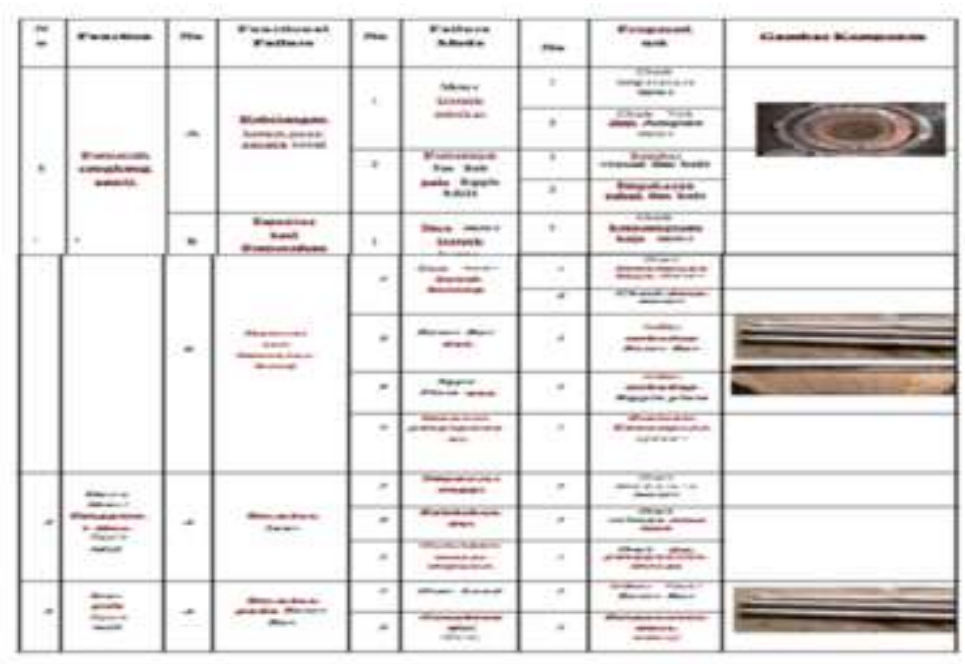

Dari tabel FMEA mengidentifikasi 17 Failure mode yang berpotensi menyebabkan terjadinya Failure Function pada komponen Mesin Ripple Mill. Dari failure Mode tersebut di identifikasi kegagalan mechanical sebesar 35,30\%.

Analisa dilakukan pula pada Failure effect terhadap komponen mesin Ripple Mill. Selanjutnya dari 17 Failure Mode akan dianalysis dengan Logic Tree Analysis (LTA). Dasar yang digunakan dalam menentukan failure mode yang akan dimasukkan dalam LTA adalah efekyang ditimbulkan terhadap sistem.

Tabel 4.3. Logic Tree Analysis (LTA)

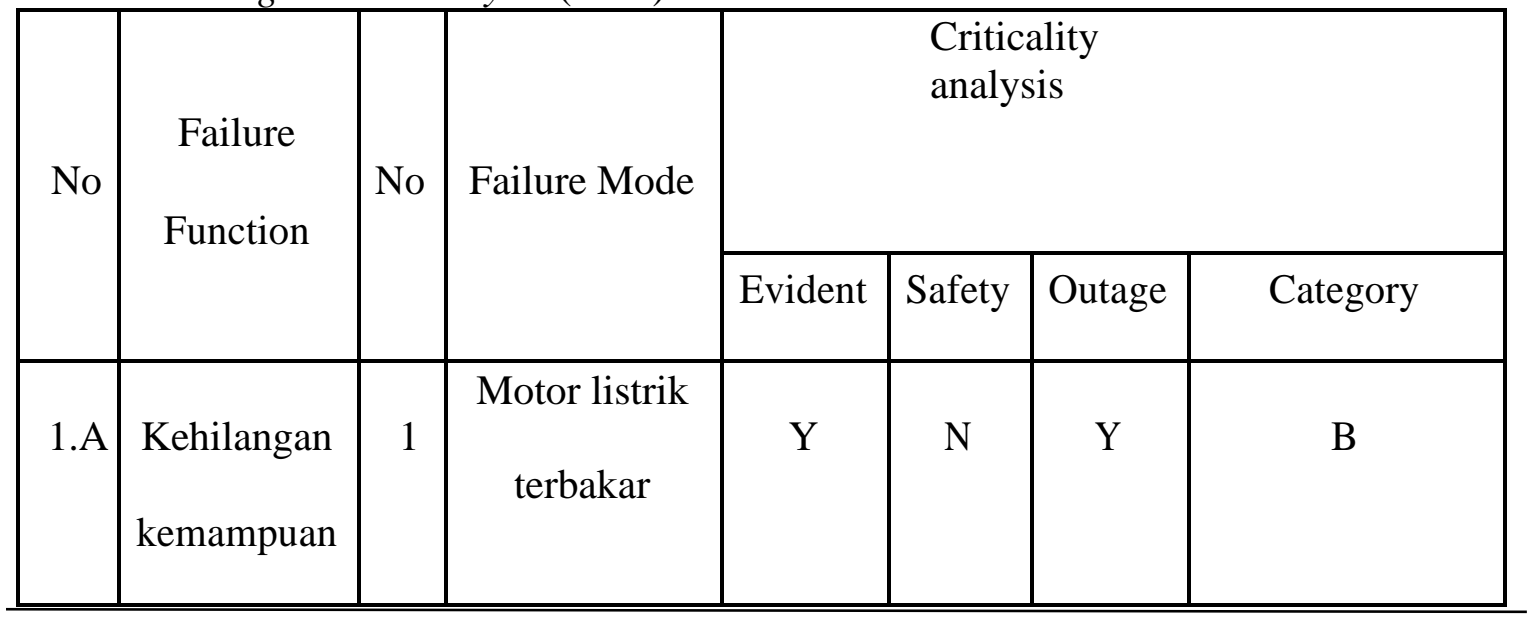

\section{Logic Tree Analysis (LTA)} Penyusunan Logic Tree Analysis

(LTA) merupakan proses yang kualitatif yang digunakan untuk mengetahu konsekuensi yang ditimbulkan oleh masing - masing failure mode. Tujuan Logic Tree Analysis (LTA) adalah mengklasifikasikan failure mode ke dalam beberapa kategori sehingga nantinya dapat ditentukan tingkat prioritas dalam penangan masing-masing failure mode berdasarkan kategorinya. 


\begin{tabular}{|c|c|c|c|c|c|c|c|}
\hline & $\begin{array}{l}\text { mesin secara } \\
\text { total }\end{array}$ & 2 & $\begin{array}{l}\text { Putusnya Fan } \\
\text { Belt } \\
\text { pada Ripple } \\
\text { Mill }\end{array}$ & $\mathrm{Y}$ & $\mathrm{N}$ & $\mathrm{Y}$ & B \\
\hline \multirow[t]{4}{*}{ 2.A } & \multirow{4}{*}{$\begin{array}{c}\text { Kapasitas } \\
\text { hasil } \\
\text { Pemecahan } \\
\text { kurang }\end{array}$} & 1 & $\begin{array}{c}\text { Daya motor } \\
\text { listrik } \\
\text { kurang }\end{array}$ & $\mathrm{Y}$ & $\mathrm{N}$ & $\mathrm{N}$ & $\mathrm{C}$ \\
\hline & & 2 & Rotor Bar aus & $\mathrm{N}$ & $\mathrm{N}$ & $\mathrm{N}$ & $\mathrm{D} / \mathrm{B}$ \\
\hline & & 3 & Ripple Plat aus & $\mathrm{N}$ & $\mathrm{N}$ & $\mathrm{N}$ & $\mathrm{D} / \mathrm{B}$ \\
\hline & & 4 & $\begin{array}{c}\text { Kesalahan } \\
\text { pengoperasian }\end{array}$ & $\mathrm{Y}$ & $\mathrm{N}$ & $\mathrm{N}$ & $\mathrm{C}$ \\
\hline \multirow[t]{3}{*}{ 3.A } & \multirow{3}{*}{$\begin{array}{c}\text { Electro } \\
\text { Motor/ } \\
\text { Penggerak } \\
\text { Mesin Ripple } \\
\text { Mill terbakar }\end{array}$} & 1 & $\begin{array}{l}\text { Temperatur } \\
\text { tinggi }\end{array}$ & $\mathrm{N}$ & $\mathrm{N}$ & $\mathrm{N}$ & $\mathrm{D} / \mathrm{C}$ \\
\hline & & 2 & Kelebihan Arus & $\mathrm{N}$ & $\mathrm{N}$ & $\mathrm{Y}$ & $\mathrm{D} / \mathrm{C}$ \\
\hline & & 3 & $\begin{array}{l}\text { Gulungan } \\
\text { tembaga } \\
\text { terputus }\end{array}$ & $\mathrm{N}$ & $\mathrm{N}$ & $\mathrm{Y}$ & $\mathrm{D} / \mathrm{B}$ \\
\hline \multirow[t]{2}{*}{ 4.A } & \multirow[t]{2}{*}{$\begin{array}{l}\text { Kerusakan } \\
\text { pada } \\
\text { Rotor Bar }\end{array}$} & 1 & Over Load & $\mathrm{Y}$ & $\mathrm{N}$ & $\mathrm{N}$ & $\mathrm{C}$ \\
\hline & & 2 & $\begin{array}{c}\text { Cangkang tebal } \\
\text { (Dura) }\end{array}$ & $\mathrm{N}$ & $\mathrm{N}$ & $\mathrm{N}$ & $\mathrm{D} / \mathrm{C}$ \\
\hline
\end{tabular}

SURYA TEKNIKA Vol. 6 No. 1, Desember 2019: 43-48 


\begin{tabular}{|c|c|c|c|c|c|c|c|}
\hline & & & & & & & \\
\hline \multirow[t]{3}{*}{ 5.A } & \multirow{3}{*}{$\begin{array}{l}\text { Kerusakan } \\
\text { pada } \\
\text { Ripple Plate }\end{array}$} & & & & & & \\
\hline & & 1 & Over Load & $\mathrm{Y}$ & $\mathrm{N}$ & $\mathrm{N}$ & $\mathrm{C}$ \\
\hline & & 2 & $\begin{array}{c}\text { Cangkang tebal } \\
\text { (Dura) }\end{array}$ & $\mathrm{N}$ & $\mathrm{N}$ & $\mathrm{N}$ & $\mathrm{D} / \mathrm{C}$ \\
\hline \multirow[t]{5}{*}{$6 . \mathrm{A}$} & \multirow{5}{*}{$\begin{array}{c}\text { Terjadi } \\
\text { Vibrasi } \\
\text { pada bearing }\end{array}$} & & & & & & \\
\hline & & 1 & pelumasan & $\mathrm{N}$ & $\mathrm{N}$ & $\mathrm{Y}$ & $\mathrm{D} / \mathrm{B}$ \\
\hline & & 2 & unbalance & $\mathrm{Y}$ & $\mathrm{N}$ & $\mathrm{N}$ & $\mathrm{C}$ \\
\hline & & 3 & Over Load & $\mathrm{Y}$ & $\mathrm{N}$ & $\mathrm{N}$ & $\mathrm{C}$ \\
\hline & & 4 & $\begin{array}{c}\text { Pergeseran } \\
\text { Bearing }\end{array}$ & $\mathrm{N}$ & $\mathrm{N}$ & $\mathrm{N}$ & $\mathrm{D} / \mathrm{C}$ \\
\hline
\end{tabular}

Hasil Logic Tree Analysis yang ditunjukkan pada Tabe 4.3, dari total 17 failure mode menunjukkan bahwa $0 \%$ kategori A hal ini dikarenakan Failure Mode tidak mempunyai konsekuensi safety terhadap personel maupun lingkungan, $11,76 \%$ diantaranya adalah kategori B karena Failure Mode mempunyai konsekuensi terhadap operasional plant yang dapat menyebabkan kerugian ekonomi secara signifikan, 35,29\% kategori C failure mode tidak berdampak pada safety maupun operational plant dan hanya menyebabkan kerugian ekonomi yang relatif kecil untuk perbaikan, 23,52 \% kategori D/B karena Failure Mode tergolong sebagai hidden Failure yang berdampak pada kerugian ekonomi secara signifikan dan 29,41\% kategori D/C karena Failure Mode tergolong sebagai hidden Failure yang berdampak pada kerugian ekonomi yang relatif kecil untuk perbaikan. Setiap terjadi gangguan pada sistem langsung ditangani oleh petugas perawatan dari hasil laporan operator pada hari itu juga.

\section{Analisa Kuantitaif}

Analisa kuantitaf bertujuan untuk menentukan komponen kritis, Probabilitas kegagalan, 
Keandalan, ketersediaan dari mesin Ripple MillKomponen Ripple mill menggunakan analisa Weibull.

1 Analisa Frekuensi Laju Kegagalan Mesin Ripple Mill

Tabel 4.4. Frekuensi Kegagalan Ripple Mill Tahun 2014 dan Tahun 2015

\begin{tabular}{llccc}
\hline & & \multicolumn{3}{c}{$\begin{array}{l}\text { Frekuensi } \\
\text { Kegagalan }\end{array}$} \\
No & $\begin{array}{l}\text { Nama } \\
\text { Mesin }\end{array}$ & \multicolumn{3}{c}{} \\
\cline { 3 - 5 } & & 2014 & 2015 & Total \\
\hline 1 & $\begin{array}{l}\text { Ripple Mill } \\
\text { no.3 } \\
\text { Ripple Mill } \\
\text { no.4 }\end{array}$ & 16 & 9 & 25 \\
\hline
\end{tabular}

Dari setiap Ripple Mill ini diperoleh datadata kegagalan (kerusakan) komponenkomponen kritis seperti terlihat dari frekuensi kegagalan setiap komponen Ripple Mill dapat dilihat pada tabel 4.5.

Tabel 4.5. Frekuensi Kegagalan

\begin{tabular}{llllc}
\hline & Rotor Ripple & & & \\
1 & Mill & 8 & 5 & 13 \\
2 & Ripple Plate & 5 & 7 & 12 \\
3 & Bearing & 6 & 2 & 8 \\
4 & Van Belt & 6 & 6 & 12 \\
\hline
\end{tabular}

\section{Analisa Laju Kegagalan}

Dari data yang dihasilkan dari penelitian Ripple Mill didapatkan interval waktu kerusakan mesin data yang diambil adalah data terakhir pada tahun 2014 dan 2015 dihitung berdasarkan jumlah jam kerusakan yang terjadi Ripple Mill seperti tabel 4.6 dibawah,

Frekuen

si

Nama

Kompon

RM3 Jumla

2 
Tabel 4.7. Hasil Regresion Failure Time mesin Ripple Mill 3 tahun 2014

\begin{tabular}{|c|c|c|c|c|}
\hline \multicolumn{5}{|c|}{ Thterval SWaktu Kerunakaie pophe $\mathrm{Am}$} \\
\hline nulan & $\begin{array}{l}\text { Popple Katil } \\
\text { Xwhen } 2014\end{array}$ & $\begin{array}{l}\text { Pupple ma1 } 3 \\
\text { Iwhan } 2015\end{array}$ & 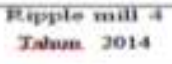 & $\begin{array}{l}\text { Eipple Min I } \\
\text { Tatum } 2013\end{array}$ \\
\hline Jemivivi & 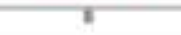 & भ & 10 & 17 \\
\hline Fetaruari & 6 & 0 & 31 & 24 \\
\hline Moter & 7 & ए & 7 & 22 \\
\hline Apent & 7 & o & 12 & 21 \\
\hline Mei & 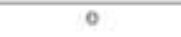 & $\circ$ & $\circ$ & 23 \\
\hline Junk & 0 & 30 & 6 & 30 \\
\hline Jwh & 45 & 0 & $\%$ & $\sigma$ \\
\hline Aewatus & 24 & 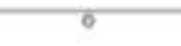 & б & 23 \\
\hline Sentembert & Tr & 23 & 8 & 20 \\
\hline Chtobex & 22 & 30 & 6 & 20 \\
\hline Nowembet & 31 & 6 & 22 & 20 \\
\hline \multirow[t]{2}{*}{ Dosembint } & 22 & 0 & 12 & 0 \\
\hline & 150 & IIT & 101 & 220 \\
\hline
\end{tabular}

\begin{tabular}{|c|c|c|c|c|}
\hline $\mathrm{t}$ & $\mathrm{F}(\mathrm{t})$ & $\mathrm{R}(\mathrm{t})$ & $\mathrm{f}(\mathrm{t})$ & Failure Rate \\
\hline & $\mathrm{CDF}$ & & $\mathrm{PDF}$ & \\
\hline 1 & 0,250582791 & 0,749417209 & 0,06930111 & 0,092473337 \\
\hline 2 & 0,302488765 & 0,697511235 & 0,040275497 & 0,057741718 \\
\hline 3 & 0,336509405 & 0,663490595 & 0,029085996 & 0,043837843 \\
\hline 4 & 0,36229162 & 0,63770838 & 0,022992437 & 0,036054782 \\
\hline 5 & 0,383214981 & 0,616785019 & 0,019109695 & 0,030982748 \\
\hline 6 & 0,400896306 & 0,599103694 & 0,016399263 & 0,027372997 \\
\hline 7 & 0,416245038 & 0,583754962 & 0,014390229 & 0,024651147 \\
\hline 8 & 0,42982741 & 0,57017259 & 0,012836374 & 0,022513138 \\
\hline 9 & 0,44202163 & 0,55797837 & 0,011595759 & 0,020781736 \\
\hline 10 & 0,453093721 & 0,546906279 & 0,010580496 & 0,019346086 \\
\hline 11 & 0,463238383 & 0,536761617 & 0,009733105 & 0,018133012 \\
\hline
\end{tabular}


Dari tabel tersebut dianalisis dengan menggunakan Weibull didapatkan nilai Betha $=(0,32057658)$ dan nilai Etha $=48,32819525$.

Berdasarkan hasil dari regresi weibull pada tabel 4.8. didapat nilai betha $=(0,149883)$ dan nilai etha $=(332,0321)$ sehingga berdasarkan dari fungsi kegagalan maka didapatkan laju kegagalan tertinggi pada 0,062787088 dan nilai terendah adalah 0,008866523 . Sehinga dapat disimpulkan bahwa kerusakan yang terjadi pada Ripple Mill 3 tahun 2015 dengan waktu 117 jam dalam satu tahun.

3 Failure Time Ripple Mill 3 tahun 2015

Tabel 4.8 . Hasil Regresion Failure Time mesin Ripple Mill 3 tahun 2015

\begin{tabular}{|c|c|c|c|c|}
\hline $\mathrm{t}$ & $\mathrm{F}(\mathrm{t})$ & $\mathrm{R}(\mathrm{t})$ & $f(t)$ & $\begin{array}{l}\text { Failure } \\
\text { Rate }\end{array}$ \\
\hline & $\mathrm{CDF}$ & & PDF & \\
\hline 1 & 0,342234857 & 0,657765143 & 0,041299158 & $\begin{array}{l}0,0627870 \\
88\end{array}$ \\
\hline 2 & 0,371719841 & 0,628280159 & 0,021883308 & $\begin{array}{l}0,0348304 \\
93\end{array}$ \\
\hline 3 & 0,389752162 & 0,610247838 & 0,015058014 & $\begin{array}{l}0,0246752 \\
44\end{array}$ \\
\hline 4 & 0,40288872 & 0,59711128 & $\begin{array}{r}0,011537 \\
3\end{array}$ & $\begin{array}{l}0,0193218 \\
59\end{array}$ \\
\hline 5 & 0,413269467 & 0,586730533 & 0,009377839 & $\begin{array}{l}0,0159832 \\
12\end{array}$ \\
\hline 6 & 0,421872561 & 0,578127439 & 0,007913604 & $\begin{array}{l}0,0136883 \\
39\end{array}$ \\
\hline 7 & 0,429229879 & 0,570770121 & 0,006853294 & 0,0120071 \\
\hline 8 & 0,435663785 & 0,564336215 & 0,006048896 & $\begin{array}{l}0,0107186 \\
03\end{array}$ \\
\hline 9 & 0,441384854 & 0,558615146 & $\begin{array}{r}0,0054170 \\
8\end{array}$ & $\begin{array}{l}0,0096973 \\
39\end{array}$ \\
\hline 10 & 0,446538425 & 0,553461575 & 0,00490728 & $\begin{array}{l}0,0088665 \\
23\end{array}$ \\
\hline
\end{tabular}




\section{Failure Time Ripple Mill 4 tahun 2014}

Tabel 4.9. Hasil Regresion Failure Time mesin Ripple Mill 4 tahun 2014

\begin{tabular}{|c|c|c|c|c|}
\hline $\mathrm{t}$ & $\mathrm{F}(\mathrm{t})$ & $R(t)$ & $f(t)$ & Failure Rate \\
\hline & CDF & & PDF & \\
\hline 1 & 0,4297656 & 0,5702344 & 0,00918275 & 0,016103463 \\
\hline 2 & 0,4361582 & 0,5638418 & 0,00463102 & $\overline{0,008213333}$ \\
\hline 3 & 0,4399229 & 0,5600771 & $\begin{array}{r}0,0031025 \\
9\end{array}$ & 0,005539576 \\
\hline 4 & 0,4426052 & 0,5573948 & $\begin{array}{r}0,0023349 \\
8\end{array}$ & 0,004189089 \\
\hline 5 & 0,4446921 & 0,5553079 & $\begin{array}{r}0,0018729 \\
3\end{array}$ & 0,003372779 \\
\hline 6 & 0,4464013 & 0,5535987 & $0,001564]_{3}$ & 0,002825379 \\
\hline
\end{tabular}

Berdasarkan hasil dari regresi weibull pada tabel 4.9. didapat nilai betha $=(0,0286688)$ dan nilai etha $=(546224660)$ sehingga berdasarkan dari fungsi kegagalan maka didapatkan laju kegagalan tertinggi pada 0,016103463 dan nilai terendah adalah 0,00825379 . Sehinga dapat disimpulkan bahwa kerusakan yang terjadi pada Ripple Mill 4 tahun 2014 dengan waktu 101 jam dalam satu tahun 


\section{Failure Time Ripple Mill 4 tahun 2015}

Tabel 4.10. Hasil Regresion Failure Time mesin Ripple Mill 4 tahun 2015

\begin{tabular}{|c|c|c|c|c|}
\hline$t$ & $F(t)$ & Fut & Fis & Failune Fute \\
\hline & IDIF & & PIF & \\
\hline L & $0.3921 \div 0993$ & 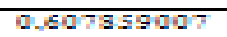 & 0.019911171 & 0.032756233 \\
\hline 2 & 0.406099185 & व.59390uan & 口.tudasass & $0.0171 \div 2 \div 09$ \\
\hline 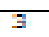 & $0_{1}=1 \div 407633$ & वy=5Egage7 & 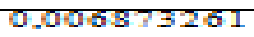 & 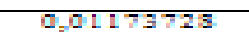 \\
\hline 4 & 0.2035556 & $0.57963 \pm \div \div$ & 0.005200007 & 0.009971193 \\
\hline 5 & $0 . \div 25022386$ & 10.57977614 & $0.00 \div 187621$ & $0 . \operatorname{0on} 739103$ \\
\hline$E$ & $0_{1} \div 28 \mathrm{~B} 500 \div 7$ & 口.571 149953 & ด.00350329 & $0,0061 \div 2502$ \\
\hline 7 & $0 \_\div 32102098$ & d.5e7s97902 & $0.003020 \div 56$ & 0.005319679 \\
\hline $\mathrm{I}$ & 0.34930758 & $\square_{y} 5 \operatorname{seng} 242$ & 0.002652951 & $0 . \mathrm{gD}=59 \div 91 \div$ \\
\hline 9 & $9.37 \div 3 \div 697$ & D.5อ25อ59 L9 & 0.002365995 & $0.00 \div 205726$ \\
\hline 10 & $0 . \div 39591525$ & 0.5อ0919474 & $0.0021355 \div 6$ & $0.003911 \div 85$ \\
\hline I. I & $0+\div \div 171969 \div$ & ด.5รazadade & $6.0019 \div 860 \div$ & 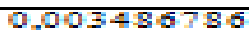 \\
\hline 12 & $0_{1} \div-3585058$ & 10.5.5414942 & 0.0017Bgs & $0.00321 \div 573$ \\
\hline 19 & $0 . \div 450 \div 934$ & $0,554 \cos 0 \mathrm{CE}$ & $0.00155 \div 537$ & 0.002982957 \\
\hline 14 & $0 . \div-6900611$ & 0.539099939 & $0.00153951 \mathrm{~B}$ & $0 . \log 2783 \div 39$ \\
\hline I.5 & $0_{1} \div \div$ B 39000 & 口.551EL0994 & $0,001 \div 39537$ & 0.002609690 \\
\hline
\end{tabular}

Berdasarkan hasil dari regresi weibull pada tabel 4.10. didapat nilai betha = $(0,065800367)$ dan nilai etha $=(40164,28)$ sehingga berdasarkan dari fungsi kegagalan maka didapatkan laju kegagalan tertinggi pada 0,032756233 dan nilai terendah adalah 0,002609696. Sehinga dapat disimpulkan bahwa kerusakan yang terjadi pada Ripple Mill 4 tahun 2015 dengan waktu 220 jam dalam satu tahun, bahwa :

\section{Ripple Mill 3}

Berdasarkan nilai betha Ripple Mill no 3 tahun 2014 yaitu 0,32057658 dan tahun 2015 adalah $0,149883<1$. Menurut Smith (2011) jika nilai Betha $<1$ maka laju kegagalan akan berkurang seiring bertambahnya waktu. Jadi pemeliharaan yang di gunakan adalah Predictive maintenance menurut M. Agus Mustofa (1997), Predictive maintenance merupakan perawatan tingkat sedang dilaksanakan untuk mengembalikan dan memulihkan sistem dalam keadaan siap dengan memberikan perbaikan atas kerusakan yang telah menyebabkan merosotnya tingkat keandalan.

\section{Ripple Mill 4}

Berdasarkan nilai betha Ripple Mill no 4 tahun 2014 yaitu 0,0286688 dan tahun 2015 adalah $0,065800367<1$. Menurut Smith (2011) jika nilai Betha < 1 maka laju kegagalan akan berkurang seiring bertambahnya waktu. Jadi pemeliharaan yang di gunakan adalah Predictive maintenance menurut M. Agus Mustofa (1997), Predictive maintenance merupakan perawatan tingkat sedang dilaksanakan untuk mengembalikan dan memulihkan sistem dalam keadaan siap dengan memberikan perbaikan atas kerusakan yang telah menyebabkan 
merosotnya tingkat keandalan. Predictive maintenance dapat dilakukan sebagai berikut :

1. Vibration Monitoring and analysis

2. Infrared Thermograpy inspection

3. Oil analysis

\section{Kesimpulan}

Fasilitas selalu dalam kondisi siap untuk dipakai sesuai dengan kebutuhan, konsepsinya semua aktivitas pemeliharaan perlu dilakukan untuk menjaga/mempertahankan kualitas asset agar selalu berfungsi dengan baik seperti kondisi sebelumnya. Adapun Kesimpulan yang dapat diambil adalah sebagai berikut :

1. Dari analisa Failure Mode Effect Analysis (FMEA) mengidentifikasi 17 Failure mode yang berpotensi menyebabkan terjadinya Failure Function pada komponen Mesin Ripple Mill. Dari failure Mode tersebut di identifikasi kegagalan mechanical sebesar 35,30 \%, Electrical $9,40 \%$ dan Instrumentation $35,30 \%$.

2. Hasil Logic Tree Analysis yang ditunjukkan pada Tabe 4.3, dari total 17 failure mode menunjukkan bahwa $0 \%$ kategori A hal ini dikarenakan Failure Mode tidak mempunyai konsekuensi safety terhadap personel maupun lingkungan, 11,76\% diantaranya adalah kategori B karena Failure Mode mempunyai konsekuensi terhadap operasional plant yang dapat menyebabkan kerugian ekonomi secara signifikan, 35,29\% kategori C failure mode tidak berdampak pada safety maupun operational plant dan hanya menyebabkan kerugian ekonomi yang relatif kecil untuk perbaikan, 23,52\% kategori D/B karena Failure Mode
Analisa ini bertujuan untuk melihat kondisi bearing pada Ripple Mill melalui lubrikasi diharapkan deteksi dini terhadap kerusakan bering dapat di lakukan. tergolong sebagai hidden Failure yang berdampak pada kerugian ekonomi secara signifikan dan 29,41\% kategori D/C karena Failure Mode tergolong sebagai hidden Failure yang berdampak pada kerugian ekonomi yang relatif kecil untuk perbaikan.

3. Hasil regression interval waktu kerusakan dari masing-masing mesin Ripple Mill, didapatkan jenis pemeliharaan yang bisa diterapkan yaitu untuk Ripple Mill 3 tahun 2014 nilai bheta adalah 0,32057658 dan Ripple Mill 4 tahun 2015 nilai bheta sebesar $0,149883<1$ dan nilai betha Ripple Mill 4 tahun 2014 adalah 0,0286688 sedangkan Ripple Mill 4 tahun 2015 adalah sebesar $0,065800367<1$, maka laju kegagalan akan berkurang seiring bertambahnya waktu. berdasarkan pola atau bentuk distribusi weibull maka jenis pemeliharaan yang tepat digunakan pada Ripple Mill 3 dan 4 adalah reactive dan inspection maintenance, Artinya pemeliharaan yang dilakukan berbasis kondisi yang dilakukan dengan cara memantau kondisi kunci peralatan yang akan mempengaruhi kondisi peralatan atau lebih dikenal dengan istilah Predictive Maintenance. Predictive maintenance dapat dilakukan sebagai berikut :

1. Vibration Monitoring and analysis

2. Infrared Thermograpy inspection

3. Oil analysis

Dari jenis pemeliharaan yang didapatkan untuk Ripple Mill, 
diharapkanumur pemakaian dan kemampuan mesin-mesin Ripple Mill bisa bertahan lebih lama dari kondisi yang diharapkan.

\section{Saran}

Diharapkan dalam pemeliharaan yang dilakukan pada mesin agar mengikuti cara-

[1] Ansori,N dan Imron.M. 2013. Sistim Perawatan terpadu (Intregeted Maintenance Systim) Edisi Pertama. Graha Ilmu, Yogyakarta

[2] Ariyanto. $2015 . \quad$ Analisis Penggantian Komponen Mesin Tube Splicing dan Mesin Tube Curing dengan Distribusi Weibull dan Perhitungan EfisiensiBiaya di PT. Gajah Tunggal Tbk. Jurnal MIX, Volume V, No. 1 Februari 2015.

[3] Asyari, 2007. Diktat Manajemen Pemeliharaan Mesin, Universitas Darma Persada - Jakarta.

[4] Azis. 2009. Penerapan Metode Reliability Centered Maintenance (RCM) Berbasis WEB pada Sistem Pendingin Primer di Reaktor Serba Guna GA Siswa Bessy. Seminar Sekolah Menengah Kejuruan, Jakarta cara atau prosedur yang sesuai dengan jenis pemelihraan yang ditetapkan, sehingga umur dari mesin Ripple Mill dan peralatan lainnya bisa beroperasi lebih lama dari jadwal yang di harapkan.

\section{DAFTAR PUSTAKA}

Nasional IV, SDM Teknologi Nuklir, 5 November 2015.

[5] Dhillon, B.S, 2006. Maintainability, Maintenance, and Reliability for Engineers, Taylor \& Francis, Boca Raton.

[6] Govil A.K., Realibility Engineering, Mc Graw Hill Publishing, 1993

[7] Hasibuan, A rahman. 2011, Proses Pemecahan Biji Kelapa Sawit Pada Mesin Ripple Mill Type RM-4000.

[8] Lubis, K. 2008. Mesin Penghancur Cangkang Kelapa Sawit. Sumatra Utara.

[9] MachineWeb. 1999. Cincinnati 5 Axis 3 Spindle. Diambil dari: www.machinetools.com (15 Juni 2016).

[10] Mashar, A. 2008. Teknik Pemanfaatan Tenaga Listrik Jilid I. Direktorat Pembinaan 